\title{
Accounting for Disability in the Phenomenological Life-World
}

\author{
Thomas Abrams and Deniz Guvenc
}

In this paper, we critically examine Edmund Husserl's philosophy of the "life-world" as found in his Crisis of European Sciences and Transcendental Philosophy. We argue that Husserl's emphasis on the transcendental nature of subjectivity ignores many of the immanent prerequisites required for subjectivity to be recognized and accorded within interpersonal interaction. To do so, we match Husserl's phenomenology with Harold Garfinkel's sociology, ethnomethodology. Ethnomethodology asks how rational conduct is made accountable in social order, and vice versa. It also suggests the interpersonal organization of the life-world can be far less egalitarian than is described in Husserl's Crisis. Subjectivity is not solely transcendental: it is, in part, made or denied in social order. Not everyone - or every transcendental subject - is allowed to participate all the time. Our argument unfolds as follows. First, we provide a sketch of Husserl's classic book and the role of the lifeworld therein, exploring both its epistemic and ontological aspects. We temper this account with Martin Heidegger's criticism of his mentor, Husserl. Heidegger argues that subjectivity, as a philosophical concept, passes over the basic structures of being-in-the-world. Next, we turn to Garfinkel's ethnomethodology, emphasizing the role of "accountability" in that project. Accountability provides us a window into some of the behavioural prerequisites required for subjectivity to be accepted as such. Finally, we turn to the world of A.B. Robillard, whose autobiographical interrogation of severe muscular dystrophy calls into question the transcendental nature of subjectivity. Like any of us, Robillard can only participate in the intersubjective life-world when particular membership requirements are met. Often, physical ability is one such requirement. However, very often it need not be; this is the very point of disability politics. We conclude by reflecting on what a phenomenology of the lifeworld sensitive to this fact might look like.

\section{Husserl, the life-world, and The Crisis}

Husserl's elaborate and often-shifting conception of the life-world is developed primarily under two modes of inquiry: epistemological and 
ontological. The epistemological inquiry into the life-world concerns the conditions of "obviousness." In other words, the life-world consists and subsists in that which is taken for granted, assumed, or self-evident in the natural attitude, in everyday conversation. In its epistemic role, the lifeworld is that which is pre-supposed in all communal dialogue: it is the condition for the possibility of communication - and thus "knowledge" among subjects. The life-world also serves as the ground of inquiry itself - and thus as the possibility of "factual truth"- for the objective sciences, since it is always in turn the object of their investigations: all perception and experience is oriented toward objects in the life-world, both scientific and non-theoretical.

It is important to note that, for Husserl, what we perceive is not the sense-data of the objects themselves, but rather "merely subjectiverelative" experiences and intuitions of the world (Husserl 125). These subjective-relative intuitions are self-evident in that they appear immediately present to us as things-in-themselves: even inductive truths stem from and make recourse to self-evident intuitions and experiences in order to be verified inter-subjectively (128). The life-world is thus the horizon for the matrix of possible intuitions and possible experiences. This horizon-characteristic of the life-world is also the condition for anticipation and prediction/projection of phenomena: for instance, when we have an intuition of one surface of an object, we often intuitively grasp the object in its "entirety" - even the surfaces and sides concealed from our direct perception. This is, in part, why even the modes of phenomena - whether they be "actual," "virtual," "illusory," "possible"are considered part of the life-world.

Ontologically, the life-world is that which our consciousness is directed toward in the natural attitude: it comprises all of the possible objects of our intentional thinking. However, any proper philosophical inquiry - that is, one that aims to inquire into the absolute ground of truth, thereby establishing it universally - must hold no pre-suppositions at all. An analysis of the life-world as pre-given in its objective totality necessitates an abstraction from the natural attitude: it requires a transcendental epoché (abstension, bracketing, reduction) from the everyday lived-experience or natural way-of-being-in-the-world. This process of abstraction is, for Husserl, the way to objective, apodictic truth. In other words, the phenomenological epoché must suspend all value statements about the ontological status of the life-world and its objects: questions of what exists or why it exists must be "put out of play" until an initial certainty is reached. Thus, ontologically speaking, the existence of the life-world is always pre-supposed in the natural attitude, but this presupposition must be exposed and bracketed in the transcendental epoché in order to reach objective knowledge. 
This method of suspending judgments concerning the life-world presents us with, in Cartesian fashion, the transcendental ego: the intentional consciousness solely capable of standing over and above the world. It is from this transcendental perspective alone that objective or universal truths can be reached, since, according to Husserl, no presuppositions are relied on in order to establish certainties. Rather, phenomena are described as they are experienced instead of being the inductive reconstruction of sense data. The transcendental subjectivity is encountered and disclosed through a reflective and reflexive process after the life-world has been bracketed along with its dominant modes of inquiry; since all other modes of inquiry in the natural attitude essentially function within isolated, self-enclosed paradigms (or worlds) and can, for that reason, never reach the ground of meaning in the first place, it is the task of a proper philosophy-for Husserl, transcendental phenomenology — to think the totality of possible "worlds." This totality of the paradigms of meaning as a horizon of possibilities is the life-world.

Throughout The Crisis the life-world and the transcendental ego are contrasted and correlated. In a certain sense, the life-world is described as "the body" of the transcendental ego: it is the condition for the subject's action and affection, as well as the condition for ontic meaningfulness. It is this ontic meaningfulness that is the basis of "the inter-subjective constitution' of the world" (168). According to Husserl, it is through the transcendental epoché that "the world as it is for us becomes understandable as a structure of meaning formed out of elementary intentionalities" (168). These intentionalities are simply conjunctive, communal processes of subjective meaning-formation, verification, and comprehension. Thus the transcendental epoché grants the understanding of the life-world as essentially meaningful, because it is constituted precisely by "a unity of meaning" (168). It is at this point-the convergence of the transcendental subjectivity and the life-world-that the epistemological and ontological inquiries are understood to be aligned and coextensive as meaning.

Yet a fundamental tension concerning the nature of the life-world here emerges: how is it possible that humans are both objects in the lifeworld and at the same time subjects of it? It seems that through intersubjective validations we invest the life-world with ontic meaning, thereby constructing and constituting it in its totality; at the same time, however, it appears that we are first and foremost constituted by the life-world itselfwe are "only a partial formation within the total accomplishment" (179). The resolution to the paradox involves a certain reflexive move in the epoché: human beings too must be considered mere phenomena and thus only the transcendental part of subjectivity must be retained. Passing back through transcendental inter-subjectivity reveals a primal "I," an ego, at its core-and this radical singularity must be the starting point for the inter- 
subjective constitution of the life world. The human being is thus the "self-objectification [...] of the corresponding transcendental 'I", (186). In other words, the life-world does both constitute human beings as such, and contain them as objects; however, the transcendental subjectivities corresponding to these bodies constitute the life-world intersubjectively by investing it with ontically valid meaning. This is the final mode in which the epistemological and ontological inquiries into the life-world are united.

This split-between humans as both objects in and subjects of the life-world-indicates a corresponding split in Husserl's understanding of subjectivity itself. On the one hand, transcendental subjectivity is the condition for our existence in and experience of the world; on the other, something like rational subjectivity, or communal membership in society, is the condition for meaning-creation and ontic verification within the lifeworld. The phenomenological reduction explains the passage between these two nodes of subjectivity; however, it risks equivocating the transcendental subject's potential for meaning-creation with the worldly subject's actual capacity to carry out meaning-creation. In other words, the social and material conditions for ontic verification and meaning-creation of and within the life-world are equivocated with a transcendental possibility: it is often the case, as disability studies makes clear, that rational, worldly subjectivity is denied to some subjects in certain contexts. This raises the question: does the phenomenological reduction pass over the conditions that make its performance possible in the first place? If transcendental subjectivity must be accessed through the phenomenological epoché, and the epoché must originate in and pass through the life-world, the possibility of performing the epoché must be accorded to and developed within the life-world. Thus communal, worldly subjectivity seems to be the condition for the recognition of transcendental subjectivity. Although all human beings might be transcendental subjects, this form of subjectivity can be barred from expression in the life-world under certain social and environmental circumstances, thereby inhibiting inter-subjective meaning-creation and verification of the life-world in those instances.

Husserl's transcendental subjectivity, arising in and yet distinct from the natural attitude, has crucial implications for scientific practice if it is to be, in fact, "scientific" in its truest sense. What is at stake in the performance of the transcendental epoche is the possibility and potentiality of new methods of ontic validation of the world, and therefore, new methods by which meaningfulness can manifest in the world. How is this the case? These stakes rest on the ongoing historical mathematization of nature, which, Husserl claims, carries with it the problem of the idealization of nature: mathematics abstracts from the life-world in order to construct a world of infinitely perfect, measurable, and lawabiding shapes. This in itself is not a problem - it is a method by which to 
know the world. The problem occurs when mathematics eclipses other modes of knowing - and knowing other worlds. Throughout history, the residue of first the Euclidean, then Galilean mathematization of nature comes not only to represent and describe the life-world, but must originally present it: there comes a point where our being-in-the-world is ruled and governed by scientific, mathematical thinking-where mathematics, logic, and science are taken as objective; where science is taken as the ground of knowledge - all of this reduces and suppresses the importance and validity of intuitive-subjective knowledge derived from basic, immediate pre-theoretical perceptions in the natural attitude.

\section{Heidegger's Critique}

Husserl's life-world is not, of course, without philosophical criticism. Here we outline that of Martin Heidegger. To grasp Heidegger's critique, we need some more detail on Husserl's understanding of intentionality. In both the Crisis and his earlier work, Husserl argues that neither rationalist nor empiricist philosophies are able to account for the directed nature of all experience. Rationalists do not sufficiently interrogate the ego of the knowing subject's inner perception. Empiricists treat "sense experience" at face value, and do not attempt to understand the conditions under which that experience becomes possible in the first place (something inherited by Kant, despite his critique of Humean skepticism). They all, Husserl maintains, lack an understanding of intentionality, the directedness of all consciousness as consciousness of something. This consciousness of something is always pursued and accomplished in the inter-subjective life-world.

Heidegger argues that the key philosophical problem is not one of sorting out where or how cognition works. Cognition is, Heidegger argues, a deeper abstraction of the more fundamental structures of worldly human existence (German: Dasein), what he calls "care." When pursuing tasksHeidegger's example is the hammering carpenter-human beings do not rationally chart a course of action, assess surrounding objects in terms of accomplishing this goal, and then perform it. Only after we perform the task can we causally assess the cognitive structures that made it possible.

In directing itself toward ... and in grasping something, Da-sein does not first go outside of the inner sphere in which it is initially encapsulated, but, rather, in its primary kind of being, it is always already "outside" together with some being encountered in the world already discovered. ... Again, the perception of what is known does not take place as a return with one's booty to the "cabinet" of consciousness after one has gone out and grasped it. Rather, in perceiving, preserving, and retaining, the Da-sein that 
knows remains outside as Da-sein (Heidegger, Being and Time $58)$.

When we describe experiences as "subjective" or "inter-subjective," we pass over the more fundamental process of care, through which the daily Being of Dasein is disclosed.

Reading human existence through "care" requires us to reconsider the basic categories of time and space. In everyday tasks, things are near and far to us not in terms of measurable centimeters or inches, but in terms of their "nearness" or "availability." The out-of-service elevator or stairwell with flimsy railings can make the objectively closest spaces out of reach for those in need of them. Similarly, clock time does not represent the temporality closest to Dasein. Dasein is "futural" in that we are always looking ahead of ourselves in our goals, and applying past moments of care as we cope with worldly tasks. ${ }^{1}$ So while Heidegger would agree with Husserl that science treats nature in a way that differs from our experience of it, he would not use the word "subjectivity" to describe our existence. More fundamentally, we exist in a world that means something to us, disclosed in unthinking, practical engagements. We could describe this in terms of "subjectivity," but a great deal of what it means to be a human being is lost in this description, notably (but not only) the time-and-spaces of care, and the tacit structures of being-in-the-world.

Because he rejects subjectivity as a useful description of human existence, for the fact that it treats being-in-the-world as a mere being, Heidegger does not use the term "intersubjectivity" when discussing communal life. Instead, he uses the term Mitsein or Mitdasein, with-being or with-there-being. Mitdasein is not intersubjectivity. The latter term presupposes a world made up of extended things, populated by knowing subjects who come into contact. This does not account for how we encounter other persons, not through mutual presence, but through worldly coexistence, through care. "The structure of worldliness of the world," Heidegger writes, "is such that others are not initially objectively present as unattached subjects along with other things, but show themselves in their heedful being in the surrounding world in terms of things at hand in the world" (116).

\footnotetext{
${ }^{1}$ Michael Schillmeier's "Time-Spaces of In/dependence and Dis/ability" provides empirical substantiation of these two categorical redefinitions. Schillmeier found that blindness emerged when socio-material arrangements let it appear. In the grocery store, for instance, visual impairment only came to the fore when those with reduced sightedness could not use past experiences of traversing grocery isles, when displays were altered (among other examples, of course). Independence ultimately relies on familiarity of times and spaces for those so embodied, not in terms of measureable times and spaces.
} 
Heidegger does not, however, use the concept of mitdasein very favourably; in Being and Time he writes that our mode of coexistence is reflected by Das Man or, "the one," as in the English expression "what one does." Das Man is the mode of existence through which we initially encounter world, and how we interact with one another. It has a leveling down effect, reducing things to their "averageness."

Thus, the they disburdens Dasein in its everydayness. Not only that; by disburdening it of its being, the they accommodates Dasein in its tendency to take things easily and make things easy. And since the they constantly accommodates Dasein, it retains and entrenches its stubborn dominance.

Everyone is the other, and no one is himself. The they, which supplies the answer to the who of everyday Dasein, is the nobody to whom every Da-sein has always already surrendered itself, in its being-among-one-another (120).

While there exists the potential to discuss our coexistence-in-the-world through Mitdasein, Heidegger does not take up that task in Being and Time (Schatzki). Instead, he uses the term to indicate how our collective existence obscures the fundamental structures of Dasein, while simultaneously indicating that it is through this average, anonymous existence where we must first uncover them (Aho).

We want to take a middle road between Heidegger and Husserl. As indicated in the previous section, we believe that there is a divide between the potential for subjectivity and the realization of subjectivity, something missed in Husserl's Crisis. We suggest that "rational subjectivity" does indeed have meaning: persons can be received as, and label themselves as, subjects (as in the lay statement "this is my subjective opinion"). However, this reception and this labeling occur in worldly coexistence. This reframes subjectivity from an existential mode of humanity to a collective achievement. As will be made clear below, there are social and material conditions that must be met for subjectivity to emerge, as a mode of human existence, albeit downstream from Dasein. We believe that these social and material conditions are put to work in the public space of with-being. This means that we need an expanded understanding of that space, outside of Heidegger's restricted formulation in Being and Time. Mitdasein is not only a source of anonymity, the sole preserve of Das Man. It is also a place where people can be regarded as subjects, members of the human community. In the next section of this paper, we want to explore the community's membership requirements, by introducing ethnomethodology, and the autobiographical, ethnomethodological disability studies of A.B. Robillard. 


\section{Ethnomethodological critiques}

In the next section of this paper, we want to introduce ethnomethodological critiques of the intersubjective basis of the lifeworld. Perhaps the word "critiques" is too strong. Ethnomethodology, as a moment in the history of social science, is one of the best sociological substantiations of phenomenology. But - and this is crucial-it has also showed that some of the concepts inherited from Husserl's Crisis need to be revisited. Here we pursue a critique of rationality, as per rational subjectivity. To do so, we will need to introduce the work of Harold Garfinkel. Next, we introduce some ethnomethodological disability studies, particularly those written by A.B. Robillard, a student of Garfinkel. Here we will find that subjectivity, as generated in the lifeworld, not only excludes forms of human meaning, it often excludes human embodiments. In short, our point is this: for Edmund Husserl, the life-world seems like a pretty lovely place. It is a world without oppression; it is a "fair game." Everyone gets to participate, everyone is given subjectivity, and subjects act rationally. When we move from existential phenomenology to the political economy of disabled personhood, we find this is not always the case.

In "The Lebenswelt Origins of the Sciences," Garfinkel and Liberman outline the lifeworld as sketched out in the Crisis, and their objections. These are quite simple. Husserl correctly outlines the "worldhorizon" underlying scientific practice in the historical parts of the Crisis, but his project is incomplete. Yes, the mathematization of nature began with Galileo, and yes, the positive sciences forget that they are projects situated within that world of both common and theoretical sense. But Husserl does not actually show, empirically, how sense making happens as a practical accomplishment, in vivo. ${ }^{2}$ This is the charge of ethnomethodology: following how members - not rational subjects, but members - produce social order.

Ethnomethodology starts with and dwells upon immediate appearances. That is to say, our issue is making adequate and evident provision for researchable, congregationally produced and concertedly accountable structures of mutually instructable actions of an ordinary society of scientists. Just how are structures of social action as witnessable properties of endogenous populations

2 Unlike Garfinkel, Husserl was not an empirical sociologist. His project was philosophical; he did not document collective human behaviour in the workplace setting (scientific or otherwise). With this established, he did do a great deal of work exploring the problem of intersubjectivity and meaning-formation both within the Crisis and in his greater oeuvre. We have chosen to read Husserl and the ethnomethodologists together, in order to bring these two perspectives into dialogue, giving both sociological support to Husserl's phenomenology, and philosophical support to Garfinkel's theoretical exploration of observed human behavior. 
actually and accountably produced? That is, produced as structured actions, in any actual case. Our interest is dedicated to locating a particular discipline's domain-specific details of lived work. These domain-specific details are available only in the open unrestricted horizons (and this "horizon" is the horizon we learned from Husserl), and infinite tasks, that compose the domain of a particular science. Scientists make their work-place-specific formal methods work. And they make them work in their details. That work, with those details, is what ethnomethodological studies of the lebenswelt are concerned to describe (Garfinkel and Liberman 7).

Focusing on the word "accountable" will make this opaque prose more manageable. Garfinkel, as Lynch's (2011) memorial tells us, began his work at Newark College with a course called "theory of accounts." He later expanded the notion of "accountability" to document how, through mundane "work," as in gestures and utterances, members of situations bring themselves and others in line with and perpetuate the prevailing social order. Not only this: members' accounts of social order serve to further organize their subject matter. ${ }^{3}$ As their critiques of Husserl show, abstract explanation is not an ethnomethodological goal: members' work is to be traced empirically.

Garfinkel et al. (1981) demonstrate the work that members perform in culturally shaping an object accountable to scientific order. They address what they call the "coroner's problem" when reflecting on a past event, on Cocke, Disney and Taylor's 1969 discovery of Pulsar NP 0532. The coroner begins with the corpse and extrapolates backwards, into its demise. Husserl's phenomenology fits this bill, as it aims at a reflexivehistorical account of the mathematization of nature, rather than an account of the action as it unfolded. The ethnomethodological goal, by contrast, is to "catch the work of fact production in flight" (Garfinkel 79). Garfinkel et al. document the means through which data was made sensible as just this data, not "noise," where a night's work yielded Pulsar NP 0532. Through meticulous review of notes and conversation analysis of audio recordings, Garfinkel et al. follow the interpersonal give-and-take, the socially organized horizon-work, in order for the optically discovered pulsar to be incorporated within the scientific lebenswelt. Mathematization is not only an historical achievement, beginning with the work of Galileo-it is also an achieved product of members" conduct in the "just-thisness" of the workplace.

\footnotetext{
${ }^{3}$ A particularly good example of this is Joan Emerson's work on "definitions of reality" in gynecological examinations, where members maintain the "exam gone right" definition-versus that of, say, "the intimate encounter"- through verbal reassurances, humour, and other ritual work. See her "Behaviour in Private Places."
} 
Garfinkel's Studies presents another important case, demonstrating how subjectivity is put to work and recognized in the social order. The study is that of "Agnes" (a pseudonym), assigned male at birth. Her move to Los Angeles and transition to female life-including sex assignment surgery-presented an emblematic case where the traditional sex-binary is revealed as a "moral order" (124). Almost all of Agnes' practical activities were moments of "passing," instances where she would comport herselfand be recognized as - naturally female. She would actively avoid her past male biography, and "case" all interpersonal exchanges where it might be detected - as in a trip to the beach (which was avoided), and thirty-five hours of interviews with Garfinkel and his research assistants. Agnes' conduct is, in part, a documented example of how Husserlian subjectivity is institutionally organized, and how Heidegger's "anyone" shapes personhood. "Feminine subjectivity" is not solely a property of female bodies; it is deployed and recognized according to collective understandings of what it means to be female. These are the "membership requirements" we introduced above. In some social situations, Agnes could easily meet them. In others, she could not. This calls into question the "essential" nature of sex or gender, an early precursor to existing debates about performative agency (Butler).

As a whole, ethnomethodology's empirical project is cause to reconsider, in part, the role of subjectivity in Husserl's lebenswelt. There is a lot going on "upstream" from subjective calculation, including work and exclusion. If we start at realized subjectivity and move backwards, we miss it; those that have not been recognized as subjects are ignored. Next, we want to introduce ethnomethdological studies of disablement, where "subjectivity," rational or otherwise, cannot be presumed and then located in those participating in the social order. It is made and denied "in and as" social order. Clarifying this point is our next task.

\section{Subjectivity-in-the-social-order}

Sociologist A.B. Robillard uses his often-peripheral location in interpersonal interaction to explore how rationality-and by extension, rational subjectivity - is generated in social organization. ${ }^{4}$ Two pieces are of interest here, his "Anger In-the-Social-Order" and "Communication Problems in the Intensive Care Unit." In the latter, Robillard documents a three-and-a-half-months stay in the hospital, the lion's share in the intensive care unit. "This fieldwork is not recommended" (Robillard, "Communication Problems" 385). Robillard's communication methods

\footnotetext{
${ }^{4}$ Robillard is diagnosed with severe muscular dystrophy. His muscular weakness requires constant use of a wheelchair. He is non-vocal, communicating through letter board or with a lip-reader's assistance.
} 
are not amenable to the business-as-usual manner through which clinical consent is afforded, or how medical consultations take place. Use of the letter board, for instance, means that sentences are formed laboriously, and do not take place in the "social consensus of "real time"" (384). Since the time required to 'do' communication does not meet the tight schedule of doctors, Robillard found that only nurses - and only some nurses - were able to engage in reciprocal communication. We write "some" because of the political economy of health care in Hawaii: nurses are flown in from mainland hospitals for brief stays because of the low domestic labour supply. "Flying nurses," as they are called, were less able to communicate in long form because their short tenures did not permit the time needed to establish routine communication. None of those whom he encountered were trained to read lips. Here, the work requirements are exactly that. Subjectivity, as a facet of rational-life-worldly interaction, requires particular workers to emerge. Here, Robillard's meditations show that existential philosophy cannot be isolated from the wider political economy (in this case of health care).

"Anger-in-the-Social-Order" documents less dire circumstances, how particular interactive moments deny subjectivity to those with atypical embodiments, causing anger on their behalf. "I am an expert on anger," writes Robillard, "a virtual black belt in giving and receiving affronts to Alfred Schütz's assumptions that we are in a common, intersubjective world" (Robillard, "Anger in-the-Social-Order" 18). At a backyard party, Robillard is excluded from conversation because he is not physically oriented, or able to physically orient, towards those with whom he could interact. So too when running into friends at the mall with his partner.

My failed attempts to initiate and maintain eye contact and conversation, as well as my unavoidably less than successful reliance on others to position me and translate for me, can be considered ethnomethodological demonstrations of the embodied commonsense knowledge used to "do" a chance meeting in the mall and to "do" a party. My anger and frustration was generated by the refusal of my body, even with the assistance of others, to exhibit the textual signs of participating in a chance meeting or party (28).

As in the intensive care unit, Robillard's exclusion from subjectivity is not an inherent attribute of his embodiment. Rational subjectivity is denied when the times-and-spaces of the interaction order are exclusive to Robillard's embodiment, resulting in what he calls an "interactive asymmetry" (17). When we pursue an historical analysis of anger-just like Husserl's historical analysis of science-we miss the just-thisness of its interactive emergence, the "in-the-social-order" where it appears as anger. 
We want to read Robillard as a phenomenologist, in thinking about the life-world. Though each of his papers stem from a distinct interactive event, the point is the same: his communication problems, both in chance meetings and medical encounters, are moments where subjectivity is "up for grabs." In some cases, it is placed out of his reach. We write "placed" for a reason: the word suggests both location and intention. In the justthisness of ritual interaction, Robillard's alternate embodiments often do not make the grade for subjectivity. Ableist sociomaterial organization, when enacted, permits some embodiments and not others. These embodiments are not, simply, shaped inadequately or biologically deficient (as in the need for a ramp). Rather, the alternate ways in which Robillard completes tasks - or "bodies-forth," to use Heidegger's phrase from the "Zollikon Seminars"-are also not accountable to the ableist rubric. Here we are thinking specifically about the measurable times-andspaces in which bodies are supposed to communicate rationally. Robillard's case demonstrates that when these are adjusted, through more attendant party guests, or nurses with the time for his means of communication, then alternate embodiments are not denied subjective status. In both cases, better accounting means that subjective rationality can be distributed more widely, and more bodies are member to the lifeworld.

\section{Returning to the Life-World}

The goal of this paper is a more inclusive life-world, both conceptually and actually. In its most basic expression, our argument is that subjectivity is not simply located at the level of the transcendental ego, as suggested in Husserl's Crisis; it is expressed and recognized in everyday life. The life-world is not only a place where pre-existing subjects come into contact. It is also a common space where subjectivity takes shape, where particular egos are able to engage in common life and, too frequently, others cannot. Not only do we want to make Husserl's lifeworld accountable to the "problem" of disability, we also want to show how a methodological reliance on "the transcendental," as a space of pure subjectivity, can obscure the immanent social and material conditions that allow persons to concretely express it. This was made evident in Robillard's autobiographic work, giving insight to the social and material passages that allow subjectivity to be realized in our shared existence. Robillard's ethnomethodology tells us that all bodies, not just his body, need to be arranged, accompanied and outfitted in particular ways to express their subjectivity. ${ }^{5}$ The goal of disability studies is to reinforce this point, with the outcome of a more inclusive life-world.

\footnotetext{
${ }^{5}$ Throughout this paper, we have referred to "disability," though we have only discussed
} physical disability. We do not wish to further exclude non-physical (or not immediately 
There is, we think, an important lesson for phenomenological philosophy in all this as well. Reading Husserl's Crisis and Heidegger's Being and Time, we get the feeling that phenomenology holds common social life in low regard. There are two extremes in the major works used in this paper. Husserl explores the natural attitude through the naturalistic attitude, quickly moving from comportment in the life-world to the thoughtless empiricism of the modern, positive sciences. The goal is to move from the life-world to the transcendent as quickly as possible. Husserl's reluctance is timid; Heidegger, pardon the pun, hammers the point home. In Being and Time, the common world is expressly that. Public life is a space of inauthenticity, the realm of the average. Our point is that in the lifeworld-or in our Mitdasein-our human mode of existence is not only inhibited. It is a place where, when persons and things are organized optimally, subjectivity is expressed. There is, so to speak, a political economy of personhood. Phenomenology should take this seriously.

\section{Conclusions}

We began this paper by sketching out Husserl's phenomenology of the life-world. The life-world is, for Husserl, the shared world of significance and meaning, pre-given in any practical enterprise. Euclidean science, as a method, must admit its grounding in the life-world. The crisis of scientific inquiry is found when the sciences lost their life-worldly grounding, when we take measured versions of nature to represent nature itself. Husserl calls this the "mathematization of nature." To recover the existential grounding of science is to understand the life-world as the necessary condition for its possibility. Husserl's book is also an exploration of transcendental subjectivity. By turning the ego on to itself, Husserl argues, we can examine the structures underpinning human experience. Here we can encounter others as pure egos, not solely as "the other." We suggested, however, that there is more to this story. In order for us to experience others, there are interpersonal requirements necessary for subjectivity to be recognized as such.

Next, we outlined Heidegger's critique of Husserl, objecting to the ontological primordiality of subjectivity. Husserl does not, Heidegger argues, question the Being of consciousness sufficiently. We are not, in the first instance, conscious subjects. Rather, we exist. By exploring everyday practical life, or our wordly "care" we can uncover the

physical) conditions further from the dialogue. A particularly good application of phenomenology to mental disability comes in Louis Sass' "Heidegger, Schizophrenia, and the Ontological Difference." Contrary to arguments that a schizophrenia diagnosis implies a different world for those so diagnosed, Sass argues that the structures of world as being-in-the-world maintain coherence, but a distinct mode of Being is made apparent. 
existential structures that make experience possible, including those of the shared world, what Heidegger calls Mitdasein. While Being and Time only addresses with-being in terms of this fundamental ontological project, we suggested that it had some important potential for the philosophy and sociology of disability. It is the open space in which persons can become subjects, should things be organize-able in their favour.

Finally, we suggested that ethnomethodology, as a phenomenological social science, gave empirical substantiation to these critiques. There we found that subjectivity is organized in the interaction order, rather than reflecting an essential attribute of human being. It is a problem of political economy. Returning to phenomenology, we argued that Husserl's epoché risked bracketing the material conditions that make subjectivity possible. This means passing over the processes whereby rationality is accorded or denied to human beings, such as those charted by Robillard's ethnomethodology. This is the space for disability studies' emancipatory project to take place. Its goal is the alignment of human existence with rational subjectivity, as full membership within the human community. In short, by tending to the boundaries of the life-world, we found the need for equal parts political economy and existential phenomenology.

\section{Works Cited}

AHO, Kevin A. "Gender and Time: Revisiting the Question of Dasein's Neutrality." Epoché 12.1 (2007)

BUTLER, Judith. Bodies That Matter: On the Discursive Limits of "Sex." London and New York: Routledge, 1993.

DREYFUS, Hubert L., and Mark A. Wrathall. "Martin Heidegger: An Introduction to His Thought, Work and Life." A Companion to Heidegger. Eds. Hubert L. Dreyfus, and Mark A. Wrathall. Malden: Blackwell, 2005. 1-16.

EMERSON, Joan. "Behavior in Private Places: Sustaining Definitions of Reality in Gynecological Examinations." Recent Sociology, Vol. 2. Ed. Hans Dreitzel. New York: Macmillan, 1970. 74-97.

GARFINKEL, Harold. Studies in Ethnomethodology. Englewood Cliffs: Prentice-Hall, 1967. 
GARFINKEL, Harold, and Kenneth LIBERMAN. "Introduction: The Lebenswelt Origins of the Sciences." Human Studies 30.1 (2007): 37.

GARFINKEL, Harold, Michael LYNCH, and Eric Livingston. "The Work of a Discovering Science Construed With Materials From the Optically Discovered Pulsar." Philosophy of the Social Sciences 11.2 (1981): 131-58.

HEIDEGGER, Martin. The Basic Problems of Phenomenology. Trans. Albert Hofstader. Revised ed., Bloomington: Indiana University Press, 1982.

-. Being and Time. Trans. Joan Stambaugh. New York: State University of New York Press, 1996.

- Zollikon Seminars. Trans. Franz Mayr, and Richard Askay. ed. Medard Boss, Evanston: Northwestern University Press, 2001.

—. "Letter on Humanism." Martin Heidegger: Basic Writings. Ed. David Farrel Krell. 2nd ed. San Francisco: Harper Collins, 1993. 213-66.

HUSSERL, Edmund. The Crisis of European Sciences and Transcendental Phenomenology; an Introduction to Phenomenological Philosophy. Trans. David Carr. Evanston: Northwestern University Press, 1970.

LYNCH, Michael. "Harold Garfinkel (29 October 1917-21 April 2011): A Remembrance and Reminder." Social Studies of Science 41.6 (2011): 927-42.

ROBILLARD, Albert. "Communication Problems in the Intensive Care Unit.” Qualitative Sociology 17.4 (1994): 383-95.

—. "Anger in-the-Social-Order.” Body \& Society 2.1 (1996): 17-30.

SASS, Louis. "Heidegger, Schizophrenia and the Ontological Difference." Philosophical Psychology 5.2 (1992): 109-32.

SCHATZKI, Theodore. "Early Heidegger on Sociality." A Companion to Heidegger. Eds. Hubert L. Dreyfus, and Mark A. Wrathall. Malden: Blackwell, 2005. 233-47.

SCHILLMEIER, Michael. "Time-Spaces of in/Dependence and Dis/Ability." Time and Society 17.2/3 (2008): 215-31. 